Original Research Paper

\title{
Technical Support of Preclinical Hydrodynamic and Functional Tests of New Medical Mechatronic Peristaltic Blood Pumps Developed by Central Research Institute of Robotics and Cybernetics
}

\author{
${ }^{1}$ Aleksandr Vitaljevich Lopota, ${ }^{1}$ Nikolai Anatoljevich Gryaznov, ${ }^{2}$ Olga Valerjevna Velichko, \\ ${ }^{1}$ Konstantin Yurjevich Senchik, ${ }^{1,2}$ Vyacheslav Valentinovich Kharlamov, \\ ${ }^{1}$ Andrey Danilovich Yukhnev and ${ }^{1}$ Galina Sergeevna Kireeva \\ ${ }^{I}$ Russian State Scientific Center for Robotics and Technical Cybernetics, 6-th Research Department, St. Petersburg, Russia \\ ${ }^{2}$ Laser Technology Center, Research Laboratory, St. Petersburg, Russia
}

\author{
Article history \\ Received: 09-11-2015 \\ Revised: 30-01-2016 \\ Accepted: 01-02-2016 \\ Corresponding Author: \\ Vyacheslav Valentinovich \\ Kharlamov \\ Russian State Scientific Center \\ for Robotics and Technical \\ Cybernetics, St. Petersburg, \\ Russia \\ Email: v.harlamov@rtc.ru
}

\begin{abstract}
The article considers the results of scientific research works on creation of hydrodynamic and functional experimental benches for preclinical physiological tests of new mechatronic peristaltic blood pumps. The conclusion states the need in carrying out such tests before the start of biological experiments involving animals. An example of the device developed at Central Research Institute of Robotics and Cybernetics-a centrifugal pump-having optimal physiological characteristics is provided. The novelty of the proposed approaches to creation of hydrodynamic and functional experimental benches, as well as their technical equipment and data obtained as a result of the experiments, form a new approach to conduct of preclinical and physiological tests of mechatronic peristaltic pumps.
\end{abstract}

Keywords: Perfusion, Perfusion Complex, Hydrodynamic Bench, Centrifugal Blood Pump, Roller Blood Pump

\section{Introduction}

Perfusion complex for extracorporeal circulation is intended for temporary full or partial replacement of the heart pump function (Kay, 2004; Reznik, 2010). It ensures optimal level of blood circulation and metabolic process in the patient's organism or in an isolated organ.

Extracorporeal circulation is mostly used in openheart and blood vessel surgery, performance of which requires exclusion of the heart from the blood circulation (Richenbacher, 1999; Argenziano et al., 1997; Westaby et al., 1997; DiSesa, 1997). Besides, such systems currently find application in oncological practice and are used for chemoperfusion treatment of malignant neoplasms (Belyayev et al., 2007; Kalinin et al., 2014; Kireeva, 2015; Belyayeva, 2011; Guseynov, 2014; Benson, 1985).

The key element of any perfusion unit is a pump, which supports continuous circulation of blood (chemotherapeutic agent solution) (Khaustov, 1998). Comparative preclinical hydrodynamic and functional tests of medical mechatronic peristaltic pumps Mars and HP-6 peristaltic pumps (in pulse mode) (Senchik, 2005) and a peristaltic pump developed by Central Research
Institute of Robotics and Cybernetics (in constant mode) were carried out at Central Research Institute of Robotics and Cybernetics (Fig. 1).

\section{Methods and Techniques}

An experimental hydrodynamic bench (Fig. 2 and 3) with circulation of model fluid in the closed loop was created for study of pump characteristics. The unit allows for connection of tubes having a diameter of 1 to $12 \mathrm{~mm}$ to the tested pump (8), measurement of pulsing flow rates and pressures in the loop, entry of data in a computer and their processing with calculation of necessary parameters. Saline is used as working fluid to ensure operation of the electromagnetic transducers; starch $\left(0.5 \mathrm{~g} \mathrm{~L}^{-1}\right)$ is added to the saline to ensure operation of the ultrasonic transducers. In order to model blood viscosity, 36\% water-glycerin mixture was used.

A measuring cell (4) allowing performance of fluid flow measurement by the ultrasound method in tubes with a diameter of 1 to $12 \mathrm{~mm}$ was designed and manufactured for mounting of an ultrasonic transducer. Signals from the ADOP analogue Doppler flow meter (3) were sent to L-154 AD converter board of Pentium-200MMX system unit (1). 


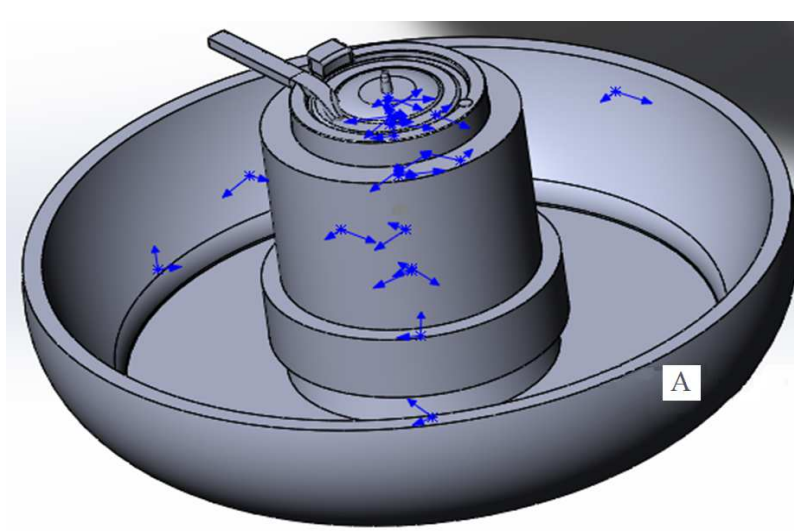

(A)

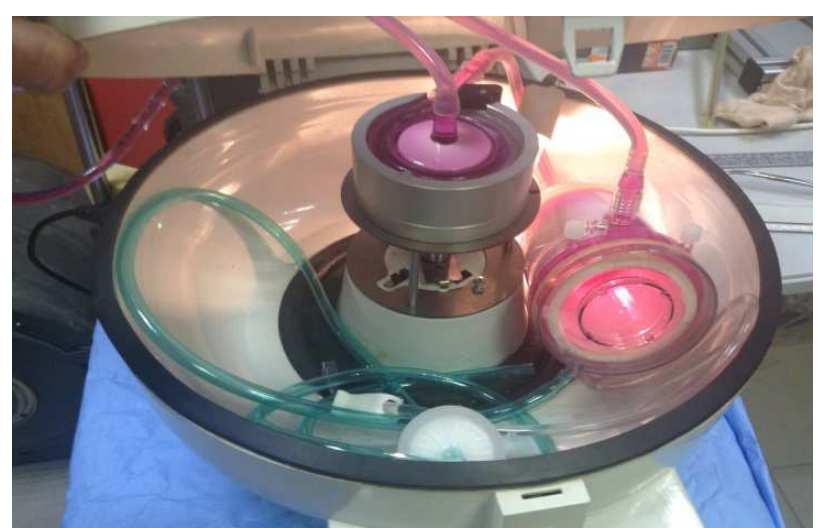

(B)

Fig. 1. Centrifugal pump developed by Central Research Institute of Robotics and Cybernetics: 3-D model in Solid Works software (A), pump assembly (B) (Senchik, 2005)
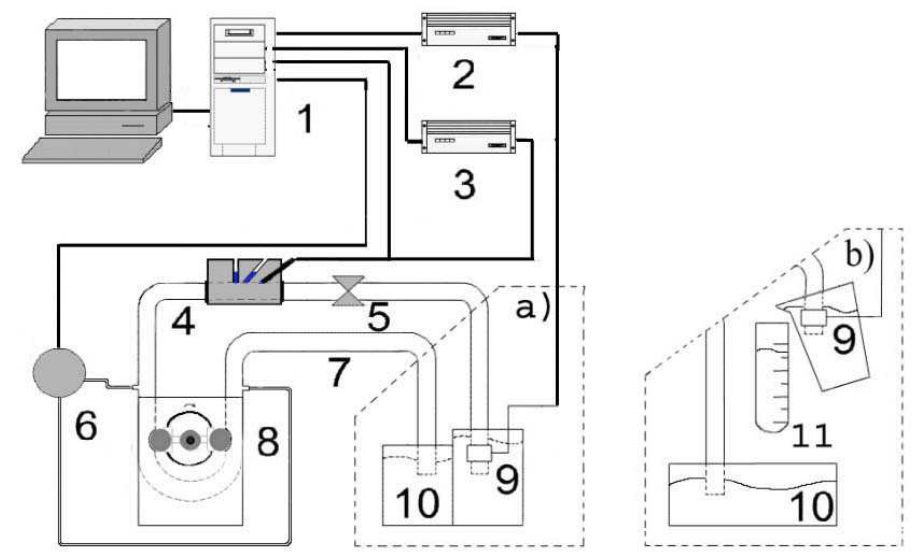

Fig. 2. Diagram of Mars pump test setup, (a) Measurements of head and rate characteristics of the pump, (b) Calibration of flow meters (see the text for description). (Senchik, 2005)

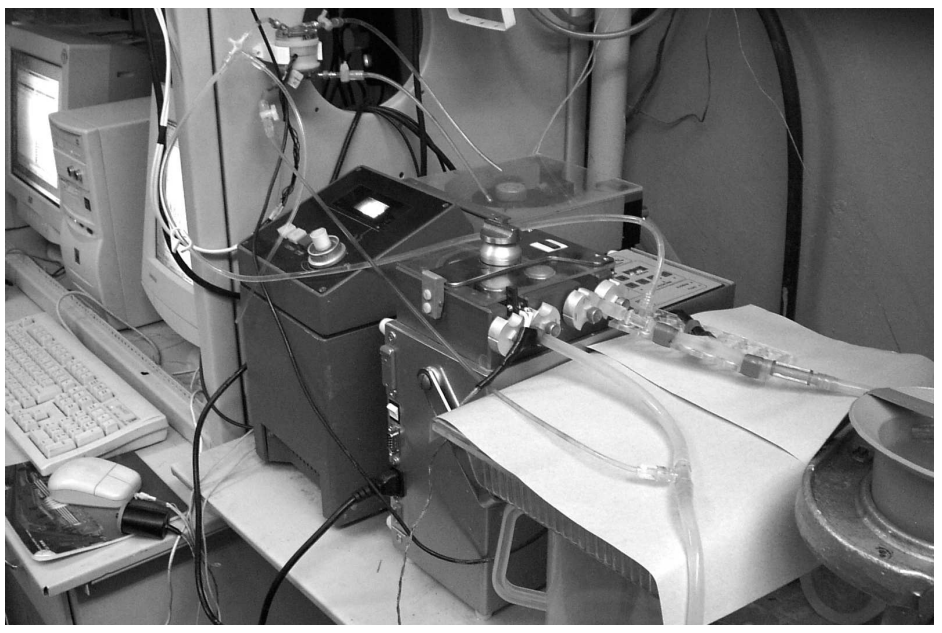

Fig. 3. Test setup for hydrodynamic characteristics of the pumps (Senchik, 2005)

A silicone tube (7) was used in the roller pump (8) as a working segment. The difference between inlet and outlet pressure is measured with a pressure sensor (6). The pressure sensor is connected to the $\mathrm{L}-154 \mathrm{AD}$ converter. 
At the outlet, the tube passes through the measuring cell (4). Ultrasonic transducer with operation frequency of 4 $\mathrm{MHz}$ is connected to ADOP unit where the signal is processed by the analogue circuit and to Spectra-300 Doppler blood flow analyzer (1) where the signal is processed digitally and displayed on the monitor in realtime. A clamp (5) that allows changing outlet/inlet pressure by pinching the tube is installed on the inlet/outlet of the pump. The pump sucks the working fluid from the tank (10). Figure 1(B) for the bench configuration used in calibration of the flow meters. In this mode, the fluid from the main outlet tube comes into the measuring cylinder (11) and then to the storage tank (10).

Pulse operation of Mars pump was tested within the following parameter range:

- $\mathrm{d}=13 \mathrm{~mm}$-inside diameter of the working segment tube

- $\quad \mathrm{T} 1=0.5-4$ sec-fluctuation time

- $\quad \mathrm{T} 2=0.4-2$ sec-pump operation time (systole)

An experimental setup (Fig. 4), which presents a system consisting of a pump (1) + hydraulic loop (2), was created for conduct of the tests.

The setup provides measurement of flow rate and pressure pulses and also entry of data into the computer (7). Water was used as the working fluid. Saline was added to the solution to support operation of electromagnetic flow meters. A silicone tube with inner diameter of $13 \mathrm{~mm}$ was used as a working segment tube. Signals from FA-100S electromagnetic sensor (4) (diameter of $10 \mathrm{~mm}$ ) were sent to Nihon Kohden MF-46 electromagnetic flow meter (5) connected to the L-154 AD converter built in the system unit of the computer. Outlet pressure is measured by the pressure sensor (3) connected to the L-154 AD converter. The pumped working fluid is held in a tank in case of opened loop A (in case of closed loop-B). There is a pump operation control system (6), which lets control time of operation and off state of the pump.

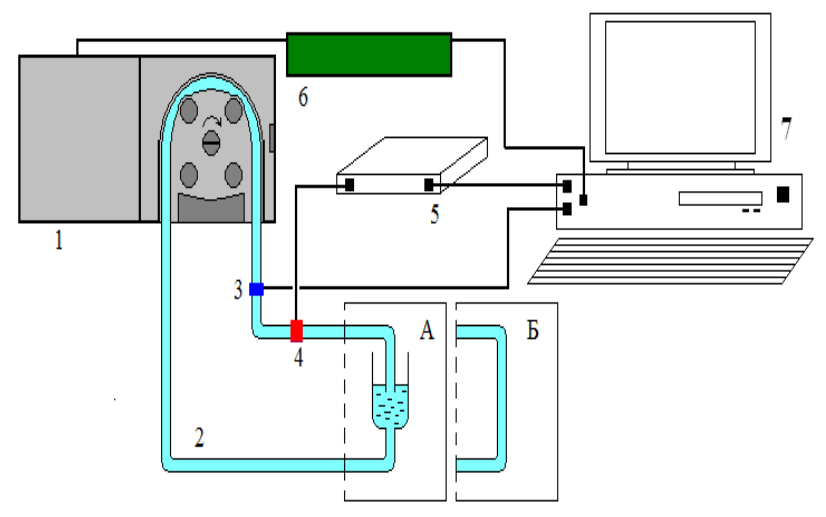

Fig. 4. Experimental setup

\section{Results}

As an example, we present the test results of Mars pump (Fig. 5). Flow of the model fluid transferred by Mars pump decreases linearly as load increases (at constant values of the pump roller head rotation speed and pinching degree of the pump segment tube). Flow of the model fluid transferred by Mars pump decreases linearly as the pinching degree of the pump segment decreases (at constant values of load and rotation speed of the pump roller head). Flow of the model fluid transferred by Mars pump increases linearly as rotation speed of the pump's roller head increases (at constant values of load and pinching degree of the pump segment tube):

$$
\begin{aligned}
& Q, \text { мл / мин. }-Q, \mathrm{ml} / \mathrm{min} \\
& n, \text { об / мин }-n, R P M \\
& d=1 \text { мм }-d=1 \mathrm{~mm}
\end{aligned}
$$

Perfusion of whole blood in the closed standard loop was performed for blood injury assessment experiments in the mentioned pumps. Quantity of free hemoglobin of blood plasma was determined upon completion of the perfusion time.

Statistically credible increase of free plasma hemoglobin content was noted both for HP-6 pump and Mars pump at the end of the surgery using $p<0.001$. In addition, the highest increase of this indicator was noted while using HP-6 pump. At the same time, free plasma hemoglobin at the end of a $4 \mathrm{~h}$ perfusion of whole blood in the closed standard loop using Mars pump was $0.154 \pm 0.012 \mathrm{~g} \mathrm{~L}^{-1}$. This indicator does not exceed the values obtained in the experiment for roller pumps of foreign manufacturers $\left(0.24 \mathrm{~g} \mathrm{~L}^{-1}\right)$ (Chang et al., 2003; De Vries et al., 2003; Fieux et al., 2009; Garcia et al., 2000; Harper et al., 2006; Linfert et al., 2009) (Fig. 6).

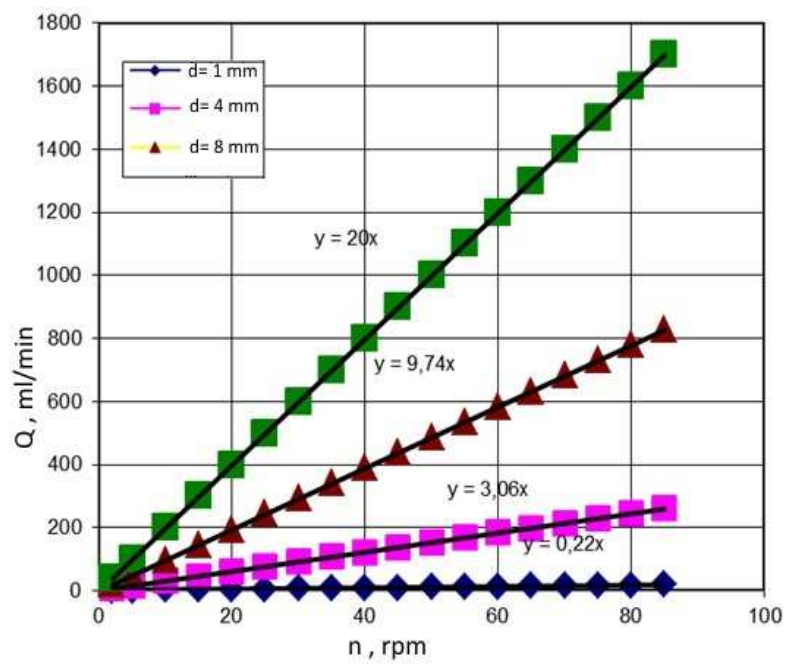

Fig. 5. Outlet flow of Mars pump (working fluid is water) Vs speed of the roller head (2-85 RPM) and diameter of the working segment tube $(1-13 \mathrm{~mm})$ 


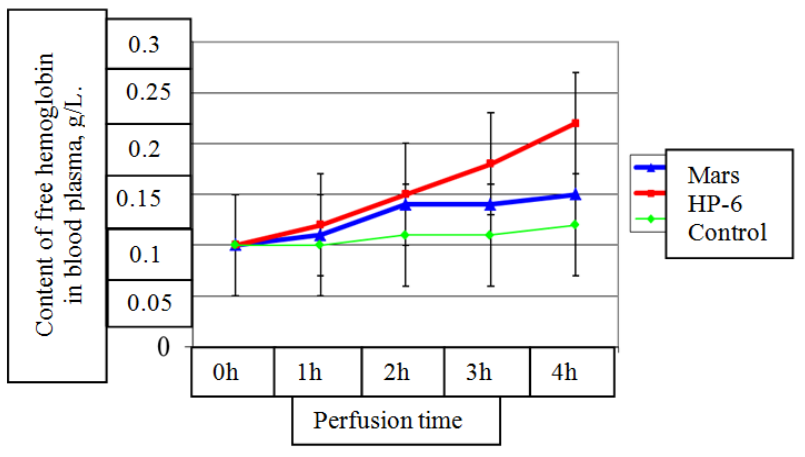

Fig. 6. Contents of free plasma hemoglobin $(\mathrm{g} / \mathrm{L})(\mathrm{M} \pm \mathrm{m})$ depending on time of circulation of whole blood in the closed loop using Mars $(\mathrm{n}=10)$ and HP-6 $(\mathrm{n}=$ 10) peristaltic pumps (Reference-literature data (Chang et al., 2003; De Vries et al., 2003; Fieux et al., 2009; Garcia et al., 2000; Harper et al., 2006; Linfert et al., 2009))

Such satisfactory performance of blood injury could be achieved due to proper precise manufacture of the roller mechanism of Mars perfusion pump and use of an advanced stepper motor with improved dynamic characteristics in the drive (Chang et al., 2003; De Vries et al., 2003; Fieux et al., 2009; Garcia et al., 2000; Harper et al., 2006; Linfert et al., 2009).

\section{Discussion}

The article provides information about technical support of the preclinical hydrodynamic and functional tests of mechatronic peristaltic medical blood pumps. As a result of the accomplished tests, we could find that the blood injury performance was at an acceptable level when testing the perfusion and centrifugal pumps manufactured by Central Research Institute of Robotics and Cybernetics and still below that level when using similar devices of different designs.

\section{Conclusion and Further Research}

In order to carry out preclinical hydrodynamic and functional study of the new medical mechatronic peristaltic pumps, it is desirable to use experimental benches created at Central Research Institute of Robotics and Cybernetics. It is reasonable to use the hardware system based on the centrifugal pump for the purpose of ensuring the physiological parameters of perfusion to perform extracorporeal circulation and perfusion treatment.

Hydrodynamic tests should precede biological and experimental study in animals for the purpose of decreasing the volumes of the latter in conformity with the principles of the evidence-based medicine.

\section{Acknowledgement}

The authors express their gratitude to the management of Central Research Institute of Robotics and Cybernetics for provided support.

\section{Funding Information}

This article was prepared with the financial support from the Ministry of Education and Science of Russian Federation for the research under the Agreement of23.09.2014, grant 14.578.21.0058 (unique identifier RFMEFI57814X0058) for the implementation of the federal target program "Research and development on priority directions of scientific-technological complex of Russia for 2014-2020 years".

\section{Author's Contributions}

Aleksandr Vitaljevich Lopota: Organized and supported research works, general editorship and critical revision.

Nikolai Anatoljevich Gryaznov: Carried out information verification, general editorship.

Olga Valerjevna Velichko: Carried out information verification, general editorship.

Konstantin Yurjevich Senchik: Performed the research and writing of the article.

Vyacheslav Valentinovich Kharlamov: Contributed to organization of works and general editorship.

Andrey Danilovich Yukhnev: Was engaged in experimental research and writing of the article.

Galina Sergeevna Kireyeva: Contributed to the research, writing the article, general editorship.

\section{Ethics}

Authors do not have any conflict of interest during the work on this article and its publication.

\section{References}

Argenziano, M., M.C. Oz and E.A. Rose, 1997. The continuing evolution of mechanical ventricular assistance. Current Problems Surgery, 34: 317-386. PMID: 9109801

Belyayev, A.M., S.F. Bagnenko and N.V. Rukhlyada, 2007. Intraperitonial Chemotherapy of Malignant Tumors of Abdominal Cavity. 1st Edn., St. Petersburg, ELBI-SPB, pp: 254.

Belyayeva, O.A., 2011. Chemoperfusion treatment of malignant. Medline Express, 2: 58-65.

Benson, A.B., 1985. Correlations between leukocyte count and absolute granulocyte count in patients receiving cancer chemotherapy. Cancer, 56: 1350-1355.

PMID: 4027873 
Chang, G.J., H.D. Mahanty, N.L. Ascher and J.P. Roberts, 2003. Expanding the donor pool: Can the Spanish model work in the United States. Am. J. Transplant, 3: 259-1263. PMID: 14510699

De Vries, A.J., Y.J. Gu, W.J. Post, P. Vos and I. Stokroos et al., 2003. Leucocyte depletion during cardiac surgery: A comparison of different filtration strategies. Perfusion, 18: 31-38. DOI: $10.1191 / 0267659103 p f 643$ oa

DiSesa, V.J., 1997. Cardiac xenotransplantation. Ann. Thorac. Surg., 64: 1858-1865.

Fieux, F., M.R. Losser, E. Bourgeois, F. Bonnet and O. Marie et al., 2009. Kidney retrieval after sudden out of hospital refractory cardiac arrest: A cohort of uncontrolled non heart beating donors. Critical Care., 13: 141-151. PMID: 19715564

Garcia, C.E., S. Bramhall and D.F. Mirza, 2000. Use of marginal donors. Curr. Opin. Organ Transplantat., 5: 50-56.

Guseynov, K.D., 2014. Hyperthermal intraperitoneal chemotherapy (HIPEC) in treatment of recurrent ovarian carcinoma. Oncology, 60: 343-347.

Harper, S., M. Nicholson, M. Kay and M. Nicholson, 2006. Leucocyte depletion improves renal function during reperfusion using an experimental isolated haemoperfused organ preservation system. British J. Surgery, 93: 623-629. PMID: 16552743

Kalinin, P.S., Y.V. Levchenko, K.Y. Senchik and A.V. Mishchenko, 2014. Isolated chemoperfusion of lung in treatment of its metastatic lesions. Oncology, 60: 673-678.
Kay, P., 2004. Techniques in Extracorporeal Circulation. 4th Edn., CRC Press, ISBN-10: 0340807237, pp: 384.

Khaustov, A.I., 1998. Development of blood pressurization systems using the experience of rocket propulsion engineering. Moscow.

Kireeva, G.S., 2015. Intraperitoneal chemoperfusion treatment of disseminated ovarian carcinoma in experiment. PhD Thesis, St. Petersburg, Falcon Print.

Linfert, D., T. Chowdhry and H. Rabb, 2009. Lymphocytes and ischemia-reperfusion injury. Transplant. Rev., 23: 1-10. PMID: 19027612

Reznik, O., 2010. The use of in-situ normothermic extracorporeal perfusion and leukocyte depletion for resuscitation of human donor kidneys. Perfusion, 25: 343-348. PMID: 20627941

Richenbacher, W.E., 1999. Mechanical Circulatory Support. 1st Edn., Taylor and Francis, Austin, ISBN-10: 1570595305, pp: 230.

Senchik, K.Y., 2005. New chromatomembrane method for gas exchange in treatment of ischemic conditions. PhD Thesis, St. Petersburg.

Westaby, S., T. Katsumata, R. Evans, D. Pigott and D.P. Taggart et al., 1997. The Jarvik 2000 Oxford system: Increasing the scope of mechanical circulatory support. J. Thorac. Cardiovasc. Surg., 114: 467-474. DOI: 10.1016/S0022-5223(97)70195-8 